\title{
Interpretation on the culture of goodness in ecological design
}

\author{
Wenchao Du \\ Arts Design Department, Tan Kah Kee College, Xiamen University, Changchou Fujian, 363000, \\ China
}

Keywords: Ecological design, Goodness, Principal part, Object, Ethics of design

\begin{abstract}
As a crucial component of Chinese social ethics, goodness reveals the essence of Human culture. As the evolvementof lifestyle, demand and values, goodness varies its way of expression on design. By analyzingand summarize the "goodness" in China's conventional culture in the expression of factor, value, process and tool, the article approaches the theoretical and practical values of modern ecological design.
\end{abstract}

\section{Introduction}

In Chinese situational context, "kindness" is an important concept. As one of the standards for Confucian aesthetic thoughts, kindness represents a moral principle or spiritual sustenance. Mencius said: "one can be kind from one's nature and this is the so-called kindness". Mencius also said: "human nature can be kind"; namely, people are basically kind. Confucian aesthetic thoughts put forward by Confucius mainly integrate moral rules. The highest principle and standard are "benevolence", which can be regarded as the integration of all kinds of "kindness". Kindness can be regarded as the extension and deepening of "benevolence", so all sorts of "kindness" in ecological design can be integrated into the definition of "benevolence".

Design, which is a type of conceptions of changing the objective world and an important part of creation activities, plans creation activities in advance. In Nicomachean Ethics, Aristotle said: "all techniques, plans, practices and selections target a certain "kindness"." [1] The ecological design includes ecological problems as the designing limitations in design, so the ecology becomes the design basis for the design science. The contents of this basis are the social system, creation activities, human being's attitude towards nature, and human being's morality and desire. Based on this, the purpose is to enhance the whole design circle's ecological design level and ecological design thought, and make the whole society including the designers, manufacturers, and consumers etc. to make contributions to the development of ecological design.

\section{Embodiment of "kindness" factors in ecological design in the broad and narrow sense}

According to the ethics, "kindness is utility of the factual property of everything for the subject's need, desire and purpose, and is the relationship attribute of everything." [2] The broad "kindness" needs to meet the three principles below, which are respectively the principle of respecting the ecological environment, the principle of protecting the ecological environment and the principle of coexistence of design and human development. The ecological design aims at reducing consumption and environmental pollution, and realizing ecological harmony. The narrow "kindness" mainly refers to pleasing people via design. The ancient Greek Cyrenaics claimed: "the feeling of joy is kindness and vice versa. Therefore, all feelings are the standards for cognition and the purposes of actions". ${ }^{[3]}$ It is obvious that the Cyrenaics considered the feeling of joy or not as the standard for measuring whether the design is good. The ecological design aims at bringing happiness to the society via design. For instance, Ergonomic Design Firm, a Swedish design group, has been designing tableware, knives and forks for the disabled since 1960s. The products designed by them bring happy use experiences to the disabled. The Wing, a sculpture created by Kiyonori Kikutake, a Japanese artist, can be considered as the artist's attempt of alleviating the ecological environment issues emerging continuously. Try to create a system, which mainly aims at the harmonious communication between human beings and nature. 
The design doesn't lack kindness but lacks eyes to finding kindness and the contacts with the essence of kindness. The design concept of ecological design is the harmony between man and nature, pays attention to the regional characteristics and ruralism, requires the consistence in design forms, regional culture, regional history and regional environment, reflects the ecological concept, expands the functions of traditional forms by fully using the symbolic nature of techniques, and emphasizes the sense of historical context by using the traditional and classical design symbols as well as popular cultural symbols.

\section{Superficial and profound value embodiments of "kindness" in ecological design}

"Kindness" is divided into the moral aspect, behavioral aspect and value aspect in Chinese traditional culture. Kindness, good mind, good deed and kind person etc. belong to the moral aspect; doing the good, praising virtue and punishing vice belong to the behavioral aspect; being stupid and naturally kind belong to the value aspect. "Kindness" is a consciousness, an embodiment of human development need, has the aspect of value characteristic. A good design must comply with the common requirements of the subject and object.

A design, which means planning, is not only the planning to drive production and consumption but also the integration, expression and transmission of deeper cultural value. The value of design, which is to find out and solve all problems in design by selecting and evaluating the design target, is embodied in three aspects: the first is to improve people's aesthetic taste, namely, the aesthetic value; the second means the practical value, which is highly goal-oriented and utilitarian; the third is to provide people with an emotional experience of spiritual sublimation, namely the ethnic value. In the 1920s, people working and learning in Bauhaus firmly believed that "a design with a good function is a beautiful one and it has a spiritual value accordingly." The designer's intention and conscious use of designing substance will generate a spiritual value. The designer's intention determines the orientation of a design in practicing the art and skills. The kindness of design is to require the designer to choose works beneficial to the society in the professional ethnic dilemma. Victor Papanek concluded the spiritual value of design into 7 aspects: associating with evil elements, performance, transformation, misleading, conveying, reform and giving a form. Giving a form was regarded as the highest spiritual value. He thought: we give a form if we are willing to face the consequences caused by design interventions and bear our social and moral responsibilities. The deep value of kindness is mainly embodied in the aspects of "aesthetics". Diderot thought that beauty is a "relationship", which, in his view, is completely objective and cannot be shifted according to people's consciousness. To show "beauty", design works needs to "simulate beautiful nature". "Beauty" and "kindness" cannot be separated. According to this, Diderot drew a conclusion: "when beauty is put in the perception of relationship, you will have its history of progress from the birth of world to now." ${ }^{[5]}$ Elements of design beauty can be divided into the design content and the artistic conception or characteristic derived from the content. They two can be considered as the internal and external parts. The internal part is revealed from the external part. People can recognize the internal part by means of the external part, because the external part has a certain guidance function.

\section{Process embodiment of "kindness" in the ecological design process}

The "kindness" in ecological design can be interpreted from the concept, technique and function. The three types of "kindness" interact as both cause and effect and influence each other

\section{Kindness of an idea}

Lao Tze said: "The highest goodness is like water. Water benefits all things and does not compete.” In the Tao Te Ching, "when everyone knows what beauty is, they will know what badness is; when everyone knows what kindness is, they will know what evil is." The soul of design works is the design concept, so what is the soul of design concept? This question is worth thinking by each designer. Papanek put forward: "a design is future-oriented and is the trial and error process for finding a meaningful order"; "a designer is the walking man on the narrow bridge between the order and chaos, freedom and emptiness, past achievements and future possibilities." The kindness in the 
design concept can be interpreted as that a designer needs to actively find the equilibrium point between the joy of consumption and environmental protection, and apply it in design. The British "practical action" organization, a non-governmental organization and including most volunteer members, has a strong sense of social responsibility and a sense of moral mission, actively participates in designs for public benefits, and benefit the extensive poverty-stricken areas and people by design. The products designed by them are practical, energy-saving, environmental and rather cheap, and well reveal the significant concept of "equality, well-being and technological justice".

\section{Kindness of technology}

The WIPO defines technology as follows in the Licensing Guide, for DevelopingCountries LicensingGuide, and for Developing Countries - WorldIntellectual Property Organization published in 1977, "A technology is the systematic knowledge about manufacturing a product, a craft used or service supplied, despite that such knowledge is reflected in an invention, a shape design, a practical new type or a kind of new plant variety, or is reflected in the technical information or skills, or is reflected in service or assistance etc. provided by an expert for designing, installing, opening or maintaining a factory or for managing an industrial and commercial enterprise or other activities." The technology is the sum of methods, skills and means used by people to change nature. Stefano Marzano, Director of Philips Design Center, pointed out that we must take the technology as a "kind" strength to be creatively used instead of an "evil" strength. ${ }^{[7]}$ The kindness in technology is shown in choosing energy-saving, environmentally-friendly and sustainable technologies, designing energy-saving, environmentally-friendly and sustainable tools, equipment and buildings according to the local natural environment, and always insisting on the concept of "being able to meet the contemporary people's need without endangering future generations' ability of meeting their needs". In the Shanghai World Expo in 2010, the ultralight power generation membrane, soybean fiber, recoverable cork wood, label paper and other materials as well as solar panels, photoelectricity integration modules and other technologies were adopted in a concentrated way. All of these are the embodiments of technological "kindness" in ecological design.

\section{Kindness of function}

In the History of Han Dynasty • Period of Emperor Xuan of Han: "The emperor held court every five days. All ministers below the prime minister needed to give statements to the emperor according to their posts, and present their memorials to test their functions." In the New Oxford English Dictionary, "kindness" is explained as "needs being satisfied or praised, representing virtue" ${ }^{[5]}$. The function and effect of design works are rather crucial. Especially for an article used in the poverty-stricken areas, its practicality must be placed in the first. In most cases, the design works can change the local people's living habit or prolong their lifespan. The humble "chimney cap” designed by the British "Practical Action" Organization for some areas is made of galvanized iron sheets, is made and installed easily, is low in cost, and can adapt to the narrow and small kitchen environment. Such a piece of ordinary design works improves the local kitchen environment, meanwhile reduces the smoke contamination caused by using solid fuel, and prolongs the local people's lifespan accordingly. ${ }^{[8]}$

\section{Indistinct and distinct embodiment of the Dao and Qi of kindness}

In the Book of Changes: "The intangible spiritual noumenon is called "Dao" and the tangible substance is called "Qi"." "Dao" refers to the abstract spiritual noumenon while "Qi" refers to the specific material carrier revealed. There is dialectical relationship between the Dao of design and Qi of design. The Dao of design refers to the design rules, design laws as well as the designer's comprehensive quality (design thought, emotion and concept); the Qi of design refers to the materials and construction technologies relied on by design. Zengzi said: "Trees can only be cut down and animals can only be killed in a proper time". As for the understanding of "Dao", Heidegger thought it is "to ponder the transcendent and fascinating things". He emphasized: "focusing on listening and belittling viewing only try to persuade people not to pursue the empirical and concupiscent things but 
to ponder the transcendent and fascinating things so that their innermost being can have the scale of God and they can have abundant internal supports and inclination."[9]

Each design works is an image composed of certain materials and directly present in front of our sense organs. The Book of Diverse Crafts said "following the natural law, properly utilizing the performance of material and skillfully applying the techniques to create a good works". "It is not about the existence of abstract concepts, but about the existence of perceptual materials available for acquaintance and appreciation out of our awareness". Sculpture, painting, architecture, music, drama, dancing, etc., none of them is excepted." ${ }^{,[9]}$ The way and tool of design are interdependent just like fish and water; a works without "way" is like water without source, and a works without "tool" is just idle theorizing. The kindness of design is to combine the way and tool of design, comprehensively consider the nature of design during the design process and give full play to the idea of "practical purposes and real learning”.

The Great Learning said: "The way of great learning lies in the enlightenment of brilliant virtues, the remolding of people and the pursuit of ultimate goodness". The concept of "benevolence" put forward by Confucius is mainly based on three levels of "kindness". As for design, they include "kindness tendency", "kindness selection" and "supreme goodness". Confucius said "choosing their merits to follow and shortcomings to correct”. These are higher requirements for design. The design should be targeted, and attention should be paid to many aspects of a piece of works. For designers, they need carefully choose those aspects that require attention.

The Book of Rites - The Great Learning said: "The way of great learning lies in the enlightenment of brilliant virtues, the remolding of people and the pursuit of ultimate goodness". Ultimate good design is the tidemark of kindness in design. My Thought explained: It is perfect when you understand the value and original meaning of kindness and also devote yourself to pursuing and achieving it through your actions. Such explanation is indeed the lowest requirements for kindness of design; "supreme goodness" is to make the design perfectly meet people's many needs. The kindness of design contains the above-mentioned three levels, and the most important thing is to achieve "supreme good all the time"; during design, insist on "do not impose what you don't like on others".

In a word, "kindness" is the main melody of ecological design, so try to achieve "kindness" during ecological design and also achieve human-society harmonious development through the design of "kindness". The ultimate goal of people reaching happiness is to reach "supreme goodness". It is a long process from "do good turns" to "supreme goodness", which determines that "kindness" as the principle of ecological design remains constant. The development of ecological design can be promoted and get on the way of sustainable development only when "kindness" gets deep into the awareness of designers and the public.

\section{References}

[1] Aristotle. Nicomachean Ethics. Translated by Miao Litian. China Social Sciences Publishing House, 1990: 8.

[2] Wang Haiming. New Ethics, Beijing: The Commercial Press, 2006: 47.

[3] Volume 2 of Lectures on the History of Philosophy, Beijing: The Commercial Press, 1960: 136.

[4] The Green Imperative - Ecology and Ethics in Design and Architecture, Written by Victor Papanek [USA] and Translated by Zhou Boyan, Beijing: China Citic Press, 2013: 48-49.

[5] Denis Diderot. Philosophy Analysis of the Root and Quality of Beauty, Collected Translations of Literature and Art Theory, first edition in 1958: 26.

[6] Han Chao. "Kindness” of Design - Analysis on British "Practical Action” Group's Care for Poor People from the Ethical Perspective. Decoration, 2015, 05.

[7] Judy Pearsall (UK). The New Oxford Dictionary of English, Shanghai: Shanghai Foreign Language Education Press, 2001: 789. 
[8] Zhang Hairong. Ecological Ethics and Ecological Aesthetics, Shanghai: Fudan University Press, 2005.

[9] Liu Gangji. Philosophy of Art, Wuhan: Wuhan University Press, 2006: 26. 